\title{
Formações imaginárias: a imagem de si e do outro em torcidas organizadas de futebol em redes sociais na internet
}

Imaginary formations: the image of itself and of the other among soccer organized twist in social networks on the internet

Formaciones imaginarias: la imagen de usted $y$ de otros en fanáticos de fútbol organizados en redes sociales en internet

Luiz Carlos Carvalho de Castro ${ }^{1}$

\section{Resumo}

CASTRO, L. C. C. de. Formações imaginárias: a imagem de si e do outro em torcidas organizadas de futebol em redes sociais na internet. Rev. C\&Trópico, v. 44, n. 1, p. 59-71, 2020. DOI: https://doi. org/10.33148/cetropicov44n1(2020)art3

Neste artigo $^{2}$, discute-se o conceito de formações imaginárias, introduzido por Pêcheux (AAD-69), com o objetivo de analisar a construção identitária de torcedores organizados. Usa-se o conceito de formações imaginárias por designar o lugar que A e B se atribuem cada um a si e ao outro, isto é, a imagem que eles fazem de seu próprio lugar e do lugar do outro, acrescido do conceito de identidade na perspectiva da AD francesa. Na metodologia, realiza-se uma pesquisa exploratória de abordagem qualitativa a partir de sequências discursivas extraídas de sites de torcidas organizadas. Os resultados apontam para a heterogeneidade da identidade do torcedor organizado, uma vez que a identidade perpassa pelas representações que cada um tem de si e do outro, pelo discurso transverso e pelo deslocamento da posição-sujeito. Conclui-se que a construção da identidade vai além das representações imaginárias, devido à pertinência dos elementos constitutivos do processo discursivo.

Palavras-chave: Identidade. Formações imaginárias. Torcedor organizado. Discurso.

\footnotetext{
Abstract

CASTRO, L. C. C. de. Imaginary formations: the image of itself and of the other among soccer organized twist in social networks on the internet. Rev. CઐTrópico, v. 44, n. 1, p. 59-71, 2020. DOI: https://doi.org/10.33148/cetropicov44n1(2020)art3

In this paper, it was discussed about the concept of imaginary formations introduced by Pecheux (AAD-69), with the objective of analyzing the identity construction of organized supporters. We use the concept of imaginary formations to

Especialista em Leitura, Compreensão e Produção Textual pela UFPE (2004) e Mestre em Linguística pela UFPB (2009). Atualmente é professor de Língua Portuguesa da Rede Estadual de Ensino do Estado de Pernambuco. Pesquisador do Núcleo de Estudos de Hipertexto e Tecnologias na Educação (NEHTE). E-mail: luladecastro@ gmail.com https://orcid.org/0000-0002-9940-0631

2 Este artigo completo é o desenvolvimento de uma comunicação apresentada na 25a Jornada Nacional de Estudos Linguísticos do Nordeste, realizado no período de 01 a 04 de outubro de 2014, na Universidade Federal do Rio Grande do Norte, campus de Natal.
} 
designate the place where $A$ and $B$ are assigned to each other and to each other, i.e, the image that they make their own place and the place of the other, plus the concept of identity from the perspective of French AD. In the methodology, we conducted an exploratory qualitative study from extracted discursive sequences of organized fan sites. The results pointed to the heterogeneity of the identity of organized fan since the identity permeates the representations that each one has of oneself and the other, the transverse displacement of the discourse and subject position. It was concluded that the construction of identity goes beyond the imaginary representations, due to the relevance of the elements (mechanisms) constituting the discursive process.

Keywords: Identity. Imaginary formations. Organized fan. Discourse.

\section{Resumen}

CASTRO, L. C. C. de. Formaciones imaginarias: la imagen de usted y de otros en fanáticos de fútbol organizados en redes sociales en internet. Rev. CßTrópico, v. 44, n. 1, p. 59-71, 2020. DOI: https:// doi.org/10.33148/cetropicov44n1(2020)art3

Este artículo analiza el concepto de formaciones imaginarias, presentado por Pêcheux (AAD-69), para analizar la construcción de identidad de los fanáticos organizados. El concepto de formaciones imaginarias se usa para designar el lugar que $A$ y $B$ se asignan entre sí y entre sí, es decir, la imagen que hacen de su propio lugar y el lugar del otro, más el concepto de identidad en Perspectiva francesa AD. En la metodología, se lleva a cabo una investigación exploratoria con un enfoque cualitativo basado en secuencias discursivas extraídas de sitios de fans organizados. Los resultados apuntan a la heterogeneidad de la identidad del aficionado organizado, ya que la identidad atraviesa las representaciones que cada uno tiene de sí mismo y del otro, por el discurso transversal y por el desplazamiento de la posición del sujeto. Se concluye que la construcción de la identidad va más allá de las representaciones imaginarias, debido a la pertinencia de los elementos constitutivos del proceso discursivo.

Palabras clave: Identidad. Formaciones imaginarias. Partidario organizado. Habla.

Data de submissão: 27/02/2020

Data de aceite: $07 / 06 / 2020$

\section{Torcida organizada para além do seu discurso}

Há décadas, as mídias vêm fomentando o discurso do futebol como a paixão nacional, alcançando a maior parte dos jovens que elegem o futebol seu esporte preferido devido à popularidade desse evento. A partir da década de 1970, houve no Brasil uma tendência à formação de torcidas organizadas com o objetivo de animarem as partidas de futebol. Segundo Máximo Pimenta (2003), a partir dos anos 1980, o 
comportamento do torcedor nos estádios de futebol mudou consideravelmente. Essa mudança deveu-se ao surgimento de uma nova categoria de torcedor: o torcedor organizado. Com o advento massivo de torcidas organizadas, surgem, em Pernambuco, nas décadas de 1980/90, as torcidas organizadas: do Náutico (Torcida Organizada Jovem Fanáutico - 1984) cujo lema é "Atitude e Disciplina”; do Santa Cruz (Torcida Organizada Inferno Coral - TOIC - 1992) que traz como lema "União e Força”; e do Sport (Torcida Jovem do Sport - TJS - 1995) que tem como lema, "Com o Sport pro que der e vier". Essas torcidas organizadas emergiram pela necessidade dos jovens ocuparem um lugar social, por uma questão de identidade que caracteriza essa geração de torcedores organizados.

Vemos em noticiários de TV, revistas e jornais que esses torcedores em seus lemas e discursos nutrem sentimentos de paixão, lealdade e fidelidade por seus times.

Na mídia digital, na internet, tem-se percebido no discurso dos torcedores organizados que as torcidas existem com a finalidade de incentivar o clube de seu time, animar as partidas de futebol e promover a paz nos estádios; no entanto, para o outro, aqui representado pelos jornalistas de futebol e torcedores não organizados, doravante, torcedores, o discurso tem sido diferente. Nos estádios, a promoção da paz e do amor tem sido trocada por atitudes de violência, gerando certo desconforto para os torcedores e a sociedade em geral, tal qual registram as mídias de comunicação de massa, especificamente nas mídias que circulam na Internet.

Neste estudo, a partir de sequências discursivas, extraídas de sites de torcidas organizadas, entre outros disponíveis na Internet, destacaremos o discurso dos torcedores organizados e o discurso do outro (jornalistas, torcedores), com o objetivo de analisar a construção identitária de membros de torcidas organizadas, concebendo o sujeito descentrado, heterogêneo, perpassado por vozes que provocam identificações de toda a sorte (CORACINI, 2003). Identificações que se projetam a partir da imagem que cada um tem de si e do outro. Para tanto, usaremos o conceito de formações imaginárias, por designar o lugar que A e B se atribuem cada um a si e ao outro, isto é, a imagem que eles fazem de seu próprio lugar e do lugar do outro, acrescido do conceito de identidade na perspectiva da Análise do Discurso pecheutiana.

\section{A rede das formações na constituição da identidade}

As formações ideológicas são constituídas por um conjunto complexo de atitudes e representações que não são individuais nem universais, mas se relacionam por meio das posições de classes em conflito umas com as outras (PÊCHEUX; FUCKS, 1975). Tais formações não constituem a maneira de ser dos indivíduos, mas se organizam mantendo entre si relações antagônicas, de alianças ou de dominação.

Essas formações caracterizam-se como um elemento de intervenção, como uma força de confronto com outras forças que, de maneira desigual, coloca em jogo práticas associadas a lugares ou relações de lugares que remetem a relações de classes quer econômica, quer não econômica. Essas reproduções das relações de classes 
são asseguradas pela existência de realidades complexas, denominadas por Althusser como "aparelhos ideológicos de Estado" (PÊCHEUX; FUCKS, 1975, p.166). A ideologia em Althusser é entendida como uma relação imaginária que os homens mantêm com as suas condições reais de existência. Nessa relação de confronto e força entre sujeitos e sociedade, podem-se inserir, no mecanismo de formação ideológica, os Aparelhos Ideológicos de Estado - o religioso, o escolar, o familiar, o jurídico, o político, o sindical, o de informação, o de entretenimento, o de clube de futebol, etc. Esses aparelhos ideológicos asseguram a difusão da ideologia da classe dominante, interpelam o indivíduo em sujeito e o colocam em uma determinada posição.

As formações imaginárias são mecanismos discursivos decorrentes das relações de força, de confrontamento entre as classes que surgem no interior de uma formação ideológica.

O conceito dessas formações foi previsto por Pêcheux (1975) ao definir na AAD-69 os diferentes elementos estruturais das condições de produção do discurso. Pêcheux determinou de início que os elementos estruturais A e B designam algo diferente de presença física, ou seja, diferente de indivíduos empíricos. Tais elementos designam lugares determinados na estrutura de uma formação social, porém para a Análise do Discurso nos processos discursivos, o que funciona é uma série de formações imaginárias que designam o lugar que A e B se atribuem cada um a si e ao outro, a imagem que eles fazem de seu próprio lugar e do lugar do outro. No discurso das torcidas organizadas, esses lugares, são representados pelos discursos dos torcedores organizados, dos torcedores comuns, da sociedade e dos jornalistas. Diz respeito a um jogo de imagens: dos interlocutores entre si, dos interlocutores com os lugares que ocupam na formação social e dos discursos já-ditos com os possíveis e imaginados. Sobre o exposto, Grigoletto (2005) afirma que "as condições de produção de um discurso envolvem não só as formas imaginárias, mas todo processo sócio-histórico e ideológico no qual um discurso é produzido, a partir de determinados lugares sociais”.

Assim, compreendemos que as formações imaginárias definem as posições que o sujeito pode ou deve ocupar no discurso, desde que seu discurso esteja inscrito numa certa formação discursiva, uma vez que uma formação discursiva é a manifestação, no discurso, de uma determinada formação ideológica. Essas posições são definidas a partir das posições, lugares que os sujeitos ocupam no contexto social, inscrita numa certa formação ideológica, como forma de antecipação, das relações de forças e sentido.

A antecipação é um elemento constitutivo das formações imaginárias que merece destaque, pois antecipadamente, o locutor " $\mathrm{A}$ ” projeta uma representação imaginária de seu interlocutor " $\mathrm{B}$ ” e vice-versa, logo, a partir das imagens pré-construídas, as estratégias discursivas vão sendo estabelecidas e os efeitos de sentido constituídos.

Grigoletto (2005), em sua tese, observa a importância do mecanismo de antecipação proposto pelas formações imaginárias, na constituição do sentido, tendo em vista que elas irão direcionar as posições que os interlocutores ocuparão no discurso. Esse mecanismo regula a argumentação, de modo que o sujeito discursiviza de um 
modo ou de outro, segundo o efeito de sentido que o locutor pensa produzir em seu interlocutor (ORLANDI, 1999).

Nesse sentido, a antecipação funciona como elemento de regulação dos efeitos de sentido no processo discursivo, em uma formação discursiva. Certamente que os membros de torcidas organizadas projetam imagens de si e do outro, aqui representado pelo adversário, torcedor comum, um cidadão, um jornalista.

A partir do reconhecimento do lugar social que o outro ocupa numa certa formação social, emergem as relações de força, outro elemento crucial para a constituição das formações imaginárias; tão importante quanto as antecipações, esse elemento intervém no processo de formações imaginárias, assim como na constituição do sentido (GRIGOLETTO, 2005). Desse modo, quando um torcedor organizado fala com outro torcedor organizado do seu clube, ele fala diferente, de que se falasse com um torcedor organizado do clube adversário, a depender do grau de confrontamento do discurso.

Portanto, é nessas relações de força, constituída a partir das posições, dos lugares, que se instaura o discurso, produzindo-se os efeitos de sentido numa relação interdiscursiva. Lembro que o sujeito é interpelado ideologicamente, assumindo, sem se dar conta, uma posição-sujeito a partir de sua inscrição em uma dada formação discursiva. No caso em estudo, na formação discursiva da torcida organizada.

Acrescente-se ainda outro elemento de igual importância para as formações imaginárias, as relações de sentido. Elas pressupõem uma relação interdiscursiva, tanto para já-ditos como para os dizeres futuros (GRIGOLETTO, 2005). Não há ponto inicial, nem ponto final para o discurso. O discurso mantém sempre relação com outros discursos realizados, imaginados e possíveis (ORLANDI,1999).

Dessa feita, compreendemos que é na rede das formações imaginárias que a identidade do sujeito se constitui.

\section{Sujeito e identidade}

Na Análise do Discurso (AD), a forma sujeito do discurso é ideológica, é efeito das formações discursivas, é resultante da relação língua e história; não é empírico, não é psicológico, não é fonte única do sentido, tampouco elemento em que se origina o discurso. Logo, o sujeito é assujeitado pela ideologia, pois ocupa um lugar a partir de uma dada formação ideológica e tem seu discurso constituído por meio de uma ou várias formações discursivas. Vimos no tópico anterior, que é na rede das formações imaginarias que o sujeito discursivo é pensado como posição, pois é a partir da posição que ocupa que se constitui sujeito de seu discurso. "Podemos agora precisar que a interpelação do indivíduo em sujeito de seu discurso se efetua pela identificação (do sujeito) com a formação discursiva que o domina” (PÊCHEUX, 1997, p. 163).

Para se falar em identidade na perspectiva da $\mathrm{AD}$, deve-se salientar que esse conceito é afetado pela dimensão ideológica e histórica do dizer, que se constrói na língua e através dela. Assim, por ser a língua flexível e em constante processo de evolução, não se pode conceber uma identidade fixa do sujeito (GRIGOLETTO, 2005 p. 126). 
Pêcheux (1997), em Semântica e Discurso, ao tratar da forma-sujeito, a partir da relação de desdobramento do sujeito do enunciado (responsável pelo dito) e do sujeito universal (saber da ciência), estabelece as diferentes modalidades que definem a posição sujeito na formação discursiva que o domina. A partir desses movimentos de identificação com a formação discursiva é que se pode na $\mathrm{AD}$ pensar a constituição da identidade.

A primeira modalidade (identificação) consiste em uma superposição entre o sujeito da enunciação e o sujeito universal, isto é, uma livre aceitação do sujeito do discurso com a forma-sujeito da Formação Discursiva (FD). Afirma Indursky (2000, p.73): "trata-se de uma identificação plena do sujeito do discurso com a forma-sujeito da FD que afeta o sujeito".

Nesse sentido, a "tomada de posição" do sujeito realiza seu assujeitamento sob a forma do "livre consentido", ou seja, de livre e espontânea vontade, caracterizando o discurso do "bom sujeito" que vai ao encontro da formação discursiva que o domina (PÊCHEUX, 1997, p. 215).

A segunda modalidade (contraidentificação) consiste em uma divisão que produz distanciamento, dúvida, questionamento, contestação e revolta contra o pensamento do sujeito universal (PÊCHEUX, 1997). Representa o discurso do "mau sujeito" pelo fato do sujeito se voltar contra o sujeito da FD por meio de uma "tomada de posição". Enfim, esse sujeito, "mau sujeito", "mau espírito" se contraidentifica com a FD que lhe é imposta, mesmo não rompendo com essa FD.

A terceira modalidade (desidentificação) surge em contrapartida às duas primeiras modalidades subjetivas da forma-sujeito por meio dos movimentos de identificação e contra-identificação do sujeito com a FD que o domina. Nessa modalidade de desidentificação do sujeito com a FD, há assim um rompimento do sujeito com a FD que lhe foi imposta. Segundo Pêcheux (1997, p. 217), “o funcionamento dessa modalidade constitui um trabalho (transformação-deslocamento) da forma sujeito e não sua pura e simples anulação".

A partir desses desdobramentos e deslocamentos a forma-sujeito não pode mais ser vista pelo viés da unicidade, os movimentos de identificação, contraidentificação e desidentificação, a forma-sujeito passa a ser percebida como heterogênea (GRIGOLETO, 2005, p.130).

Assim, entendemos que esses movimentos são constitutivos da identidade que vai constituindo-se de forma heterogênea a partir de uma FD que domina o sujeito.

\section{Da teoria à prática: análise da constituição da identidade de torcedores organizados}

Nossa análise parte de sequências discursivas (SDS) extraídas de site de torcidas organizadas ${ }^{3}$ disponíveis na Internet. Parte-se do pressuposto de que os torcedores organizados pensam ser criadores de seus discursos, fonte de origem dos sentidos,

TOIC - Torcida organizada Inferno Coral - Disponível em: https://www.facebook.com/grtoicoficial acessada em: 18/mai/2014. 
não se dando conta de que, ao produzirem tais discursos, estão assujeitados a uma ou várias Formações Discursivas (FDs). É no interior das FDs que os sujeitos interpelados ideologicamente inscrevem seu discurso, ocupando determinadas posições, lugares na conjuntura social. Esses lugares, essas posições que nos remetem a relações de classe (poder) se caracterizam pelo afrontamento de posições políticas e ideológicas, organizados em formações que mantêm entre si, relações de antagonismo, de aliança ou de dominação (PÊCHEUX; FUCHS, 1975).

Pêcheux parte da hipótese de que esses lugares estão representados nos processos discursivos em que são colocados em jogo, não como feixe de traços objetivos, mas sim transformados, como representações imaginárias. Essa hipótese o leva a concluir que "o que funciona nos processos discursivos (formações discursivas) é uma série de formações imaginárias que designam o lugar que A e B se atribuem cada um a si e ao outro, a imagem que eles se fazem seu de próprio lugar e do lugar do outro"(PECHEUX, 1997, p. 82).

Para esse autor, o discurso é "efeito de sentido entre os pontos $A$ e B", em que os pontos A e B diferentemente de sujeitos empíricos, representam lugares, posições sociais que estabelecem relações entre interlocutores.

A análise será guiada à luz de um dos fatores das condições de produção do discurso: o jogo de imagens. Tomarei como modelo o esboço sugerido por Pêcheux (1997, p. 83) para analisar como a posição (as imagens de si e do outro) dos membros de torcidas organizadas interfere na constituição da identidade.

Tabela 1: Formações discursivas dos torcedores organizados e comuns.

\begin{tabular}{|c|c|c|}
\hline $\begin{array}{l}\text { Expressão que } \\
\text { designa as formações } \\
\text { imaginárias }\end{array}$ & Significação da expressão & $\begin{array}{l}\text { Questão implícita cuja } \\
\text { "resposta" subentende a formação } \\
\text { Imaginária correspondente }\end{array}$ \\
\hline${ }^{\mathrm{I}} \mathrm{A}^{(\mathrm{A})}$ & $\begin{array}{l}\text { Imagem do lugar de A para o } \\
\text { sujeito colocado em A }\end{array}$ & "Quem sou eu para lhe falar assim?" \\
\hline${ }^{\mathrm{I}} \mathrm{A}^{(\mathrm{B})}$ & $\begin{array}{l}\text { Imagem do lugar de B para o } \\
\text { sujeito colocado em A }\end{array}$ & $\begin{array}{c}\text { "Quem é ele para que eu lhe fale } \\
\text { assim?" }\end{array}$ \\
\hline${ }^{\mathrm{I}} \mathrm{B}^{(\mathrm{B})}$ & $\begin{array}{l}\text { Imagem do lugar de B para o } \\
\text { sujeito colocado em B }\end{array}$ & $\begin{array}{c}\text { "Quem sou eu para que ele me fale } \\
\text { assim?" }\end{array}$ \\
\hline${ }^{\mathrm{I}} \mathrm{B}^{(\mathrm{A})}$ & $\begin{array}{l}\text { Imagem do lugar de A para o } \\
\text { sujeito colocado em B }\end{array}$ & "Quem é ele para que me fale assim?" \\
\hline
\end{tabular}

Fonte: Elaboração própria.

Nota: A - o torcedor organizado.

B - o outro (torcedor comum, jornalista, cidadão).

Sabemos que os discursos são enunciados a partir de uma ou várias formações discursivas, as quais determinam "o que pode e o que deve ser dito a partir de uma 
dada posição”. Essas posições, das quais dependerá o sentindo das palavras, estabelecem relações de poder assimétricas, de acordo com a posição de onde se fala.

Neste artigo, concebe-se o discurso como efeito de sentido entre os interlocutores aqui representados pelos torcedores organizados e o outro torcedor comum, jornalista.

\subsection{O torcedor organizado: a imagem que tem de si}

SD1 - É tudo nosso! A maior, a mais apaixonada! Somos superior. $\mathrm{T}$

SD2 - a maior do nordeste tudo nosso... $\bullet$ :

SD3 - Queria q voltasse a ser a mesma TOIC de antes. Sem bairrismo, falta de respeito entre componentes. Cadastramento é importante, sempre bati nesta tecla. Ainda tenho minha carteirinha de sócia componente daí, bons tempos que não me arrependo. Já q o poder público não resolve, vamos tentar organizar a casa.

SD4 - Inferno vamos se inteligente chama os reporteres da uma coletiva dizendo que a inferno coral não aceita esse tipo de atitude e expulsa os 3 vandalos.

A partir dos movimentos de identificação e contraidentificação com a formação discursiva é que se pode, na $\mathrm{AD}$, pensar a constituição da identidade. As Sequências Discursivas (SDs) 1 e 2 mostram a constituição da identidade dos torcedores organizados por meio do movimento de identificação que ambos têm com a formação discursiva que os domina: Torcida Organizada, como movimento de jovens torcedores, cujo discurso é de superioridade e superestima. Já nas SDs. 3 e 4, o movimento é de contraidentificação, pois a TOIC já não é como antes, devido à rivalidade entre as torcidas e à falta de respeito entre seus próprios membros e a violência. Esses movimentos colocam em "xeque" a quebra da unicidade tanto do discurso quanto da identidade devido ao deslocamento da posição-sujeito do torcedor organizado. Confirmando assim, o que já observara Grigoletto (2005), que "na trama das formações imaginárias, tomada sob uma perspectiva discursiva, há lugar para diferentes e, algumas vezes, até contraditórias representações”.

SD5-Queremosvertodososcomponentesnessaaçãosocial, todos estão convidados. 
Figura 1: Cartaz da Campanha "Doação de Sangue da TOIC".

\section{"DOAÇ̃̃O DE SANGUE DA TOIC"}

VOCÊ ESTÁ CONVIDADO A COMPARECER NO DIA 19/07 [SABADO] DAS 9:00 ÀS 16:00 HORAS.

\section{LOCAL: SEDE SOCIAL DA INFERNO CORAL (aRRUDA]}

EM SEGUIDA VAMOS ASSISTIR EM NOSSA SEDE 0 JOGO ENTRE, VILA NOVA X SANTA CRUZ EM UM SUPER TELĀO EM NOSSA SEDE.

COMPARECQA ,AJUDE QUEM PRECISA, INFERNO CORAL FAZENDOO BEM ,SEM OLHAR A QUEM!

Fonte: https://www.facebook.com/grtoicoficial.

SD6 - Vamos lá, todos os membros são solidários, Inferno Coral fazendo o bem sem olhar a quem!

Figura 2: Cartaz da Ação Social de Inverno.

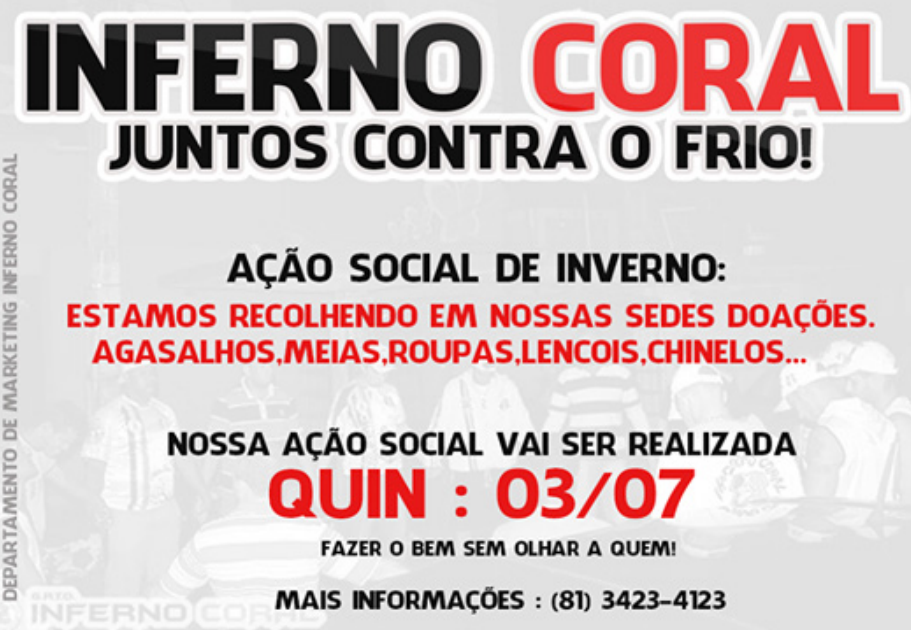

Fonte: https://www.facebook.com/grtoicoficial. 
SD7 - Nem todos nós temos o mesmo tempo / Doe vida Doe Sangue

Figura 3: Cartaz da Campanha Doe Vida - Doe Sangue.

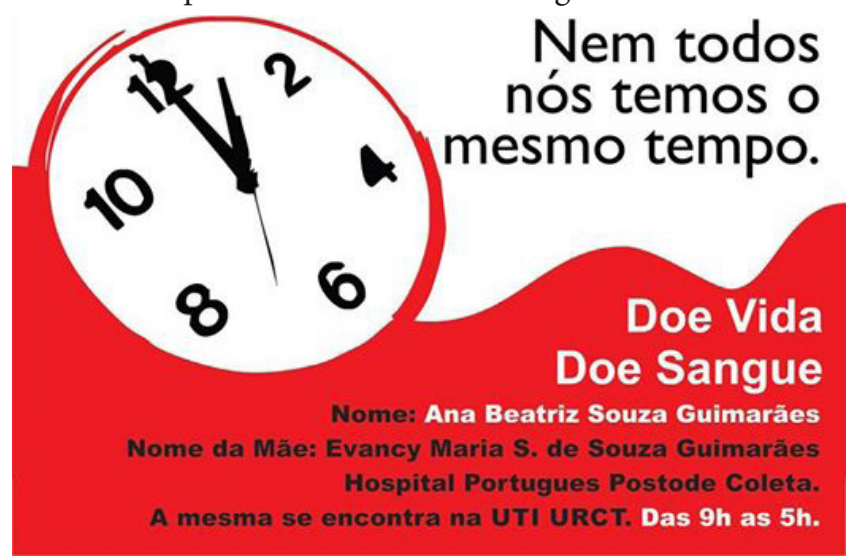

Fonte: https://www.facebook.com/fanautico.com.br.

As SDs. 5, 6 e 7 apresentam o discurso assistencialista, atravessado por discursos de outras FDs, tais como o discurso religioso "fazei bem aos que vos odeiam" (LUCAS 6, p. 27); e do dito popular "fazei o bem sem olhar a quem". Esses interdiscursos são constitutivos do discurso, onde todos os dizeres/saberes circulam (GRIGOLETTO, 2005). É notório do discurso do torcedor organizado que o fazer o bem pode calar a boca de outros que os descrevem como pessoas do mal, pelo simples fato de ser membro de uma torcida organizada. O discurso solidário segue com a torcida da FANAUTICO na SD7.

\begin{abstract}
SD8 - Nas torcidas organizadas tem muito pra ser mostrado, como campanhas de doação de sangue, de alimentos, de agasalhos; Pessoas que largam tudo para se dedicar somente a sua torcida, para fazer ela ficar cada vez melhor, torcedores brancos, negros, adolescentes, jovens, idosos, homens, mulheres, brasileiros ou não que se reunem em prol de todos sem nenhum tipo de preconceito por credo, raça ou cor. Mas isso a "globo" não mostra, ela só quer mostrar o lado ruim para botar todos contra nós integrantes de torcida organizada.
\end{abstract}

Na SD8, o torcedor organizado em seu discurso fala do sujeito do bem que o membro de uma torcida organizada é aquele que também pratica ações sociais, mas que a mídia não mostra, antes, só mostra o lado ruim, com a finalidade de promover a discórdia entre os torcedores organizados e o resto da população. 


\subsection{O torcedor organizado: a imagem que o outro tem dele}

O torcedor organizado constrói de si mesmo uma imagem e, além disso, constrói a imagem que o outro tem dele, antes mesmo da enunciação, mas é na prática discursiva que essas projeções se constituem produzindo efeitos de sentido. Essas projeções, denominamos de antecipação, elemento constitutivo das formações imaginárias que leva o locutor a projetar uma representação imaginária de seu interlocutor e ainda a imagem que ele pensa representar para seu interlocutor. Tendo em vista que as antecipações direcionarão as posições que os interlocutores ocuparão no discurso (GRIGOLETTO, 2005).

SD9 $^{4}$ - Sabemos que somos mal vistos, que somos vistos como margionais, bandidos e desocupados, só que muita gente não sabe o trabalho de uma organizada, não sabem de nossa realidade e assim como em todo meio onde há a convivência entre pessoas existem pessoas de má indole e desonestas, mais existem também aquelas pessoas que lutam pela sua sobrevivência e seu reconhecimento através de seu trabalho [...].

$\mathrm{SD}^{5}$ - Essas porcarias de "torcidas" organizadas não acrescentam nada aos seus respectivos clubes. Aliás é um monte de vagabundo que vive faturando dinheiro com a venda de materiais, explorando o nome e a imagem do clube. Tá na hora de nós, torcedores do bem, acabarmos com esses vermes.

Pelo mecanismo de antecipação, o torcedor organizado descreve a si mesmo a partir do que ele imagina representar para o outro, com a finalidade de contra-argumentar o discurso do outro. A partir da projeção da imagem do bom sujeito que luta para sobreviver e trabalha (SD-9), pois, é assim que o torcedor organizado também pode ser visto. $\mathrm{Na}$ (SD-10) o torcedor comum, representa a si e aos outros torcedores comuns como "torcedores do bem" capazes de dar fim à violência.

Desse modo, o torcedor organizado na SD-9, e o torcedor comum na SD-10 regulam seu argumento, discursivizando, de um modo ou de outro, segundo o efeito de sentido que o locutor pensa produzir em seu interlocutor, a fim de produzir efeitos de sentido que projetem o torcedor do bem para seus interlocutores (ORLANDI, 1999). Além disso, atente-se para os deslocamentos feitos inconscientemente pelos torcedores que ora assumem o discurso do outro, contraidentificando-se com a FD que os domina, ora identificam-se projetando o torcedor do bem que luta pela melhoria do seu clube.

\footnotetext{
4 http://www.organizadasbrasil.com/papo-reto.

5 Fonte: http://blogs.diariodepernambuco.com.br/esportes/2014/02/22/o-dia-em-que-a-organizada-foi-vaiada-pela-verdadeira-torcida-do-sport/.
} 
É por meio dos deslocamentos que vão sendo projetadas as imagens do bom e mau torcedor, constitutivas do torcedor organizado que, inconscientemente, encontra-se interpelado ideologicamente e inscreve-se como sujeito em uma formação discursiva que o domina, ora identificando-se com ela, ora contraidentificando-se, constituindo, assim, a identidade do torcedor organizado

\section{Considerações finais}

Este trabalho tratou das formações imaginárias na perspectiva pecheutiana com o objetivo de investigar as construções identitárias de torcidas organizadas, a partir de sequências discursivas extraídas da internet. As sequências discursivas (SDS) analisadas desvendaram a complexidade da constituição da identidade dos torcedores organizados que se inicia com as formações imaginárias, ponto de partida neste estudo. Nas SDS. (1, 2, 3 e 4), a identidade dos torcedores organizados foi pensada a partir do movimento de identificação e contraidentificação a partir das diferentes posições-sujeito do torcedor organizado, confirmando a heterogeneidade constitutiva do sujeito. Na continuidade das análises, as SDS. $(5,6,7$ e 8$)$ apontaram para uma identidade constituída a partir do atravessamento dos discursos de outras Formações Discursivas. Os argumentos para projetar a imagem do torcedor do bem passaram pelos discursos assistencialista e religioso com a finalidade de produzir um efeito de sentido no interlocutor que passa a visualizar a torcida organizada por uma ótica diferente daquela apresentada pela mídia, que só projeta o "torcedor do mal".

Já nas SD 9 e 10, as representações imaginárias assumem a responsabilidade total a partir da imagem que o outro tem do torcedor organizado e a imagem que o torcedor organizado pensa representar para o seu interlocutor, ativando o mecanismo de antecipação que não só é constitutiva da identificação, como também da produção do sentido, gerando efeitos de sentidos entre os interlocutores.

Assim, tecemos a trama da construção da identidade de torcedores organizados, seguindo uma trajetória que vai desde as formações imaginárias, passando pelo discurso transverso e pelo deslocamento da posição-sujeito, ratificando a heterogeneidade na construção identitária. 


\section{Referências}

CORACINI, Maria José R. F. Subjetividade e Identidade do(a) Professor(a) de Português. In: (Org.). Identidade \& discurso: (des)construindo subjetividades. Campinas: Editora da UNICAMP; Chapecó: Argos, 2003, p. 239-255.

GRIGOLETTO, Evandra. O discurso de divulgação científica: um espaço discursivo intervalar. Tese de Doutorado. Porto Alegre: Curso de Pós-Graduação em Letras/ UFRGS, 2005.

INDURSKY, Freda. A fragmentação do sujeito em análise do discurso. In: INDURSKY, Freda \& CAMPOS (org). Discurso, memória, identidade. Porto Alegre, Sagra-Luzzatto, 2000, p. 70-81.

PÊCHEUX, Michel. Semântica e Discurso: uma crítica à afirmação do óbvio. Campinas, SP: UNICAMP, 1997.

PÊCHEUX, Michel \& FUCHS, Catherine. A propósito da análise automática do discurso: atualização e perspectivas. In: GADET, Françoise. \& HAK, Tony (org.). Por uma análise automática do discurso. 3 ed. Campinas: Ed. da UNICAMP, 1997.

A análise do discurso: três épocas (1983). In: GADET, Françoise. \& HAK, Tony (org.). Por uma análise automática do discurso. 3 ed. Campinas: Ed. da UNICAMP. 1975.

ORLANDI, Eni Pulcinelli. Análise de discurso: princípios e procedimentos. Campinas, SP: Pontes, 1999.

PIMENTA, Carlos Alberto Maximo; ALBERTO, Carlos. Torcidas organizadas de futebol: identidade e identificações, dimensões cotidianas. Futbologías: Fútbol, identidad y violencia en América Latina, Buenos Aires: CLACSO, p. 39-55, 2003. 